\title{
Rasgos centrales del agronegocio en Latinoamérica: la experiencia en Uruguay
}

\section{Mauricio Ceroni*}

Perfiles Latinoamericanos, 26(52) | 2018

DOI: $10.18504 / \mathrm{pl} 2652-004-2018$

Recibido: 24 de agosto de 2015

Aceptado: 7 de noviembre de 2017

\section{Resumen}

Durante las últimas décadas el flujo de capitales globales encontró un atractivo de inversión en América Latina, y a través del modelo del agronegocio ha modificado la estructura agraria de muchos países de la región. El presente artículo describe y analiza la forma en que el agronegocio se ha expandido en Latinoamérica, en particular en sus distintas fases en Uruguay. Se concluye que para ello han sido claves el papel de los Estados Unidos, el aumento de la inversión extranjera directa, el rol de los Estados nación y el control del territorio por parte del capital transnacional.

\begin{abstract}
During the last years, the flow of global capitals found an attractive investment in the Latin American agrarian space. This modified the agrarian structure of many of these countries through the agribusiness model. The present article describes and analyzes the way this model has expanded in Latin America, and in particular, its different phases in Uruguay. Finally, it points out that the central elements of the agribusiness model expansion are the following: the role of the United States, the foreign direct investment increase, the nation State function, and the transnational capitals control in the territory.
\end{abstract}

Palabras clave: agronegocio, América Latina, espacio agrario, inversión extranjera directa, capital transnacional, Uruguay.

Keywords: Agribusiness, Latin America, agrarian space, foreign direct investment, transnational capital, Uruguay.

* Maestro en Ciencias Ambientales por la Universidad de la República (Uruguay), candidato a doctor en Geografía por la Universidad Nacional Autónoma de México (UNAM) | mceroni@ei.udelar.edu.uy 


\section{Introducción ${ }^{1}$}

istóricamente, América Latina se ha integrado a la división internacional del trabajo como proveedora de bienes primarios, lo que ha generado su inserción en el mercado mundial de forma diferencial. Este rasgo del modo de producción capitalista, siguiendo a Galeano (2004), provoca que unos países se especialicen en ganar y otros en perder, lo que ha resultado en establecer un sistema-mundo de jerarquías y desigualdades, situando a América Latina como un claro perdedor. Una de las tantas evidencias que muestran esta relación fue el permanente saqueo de bienes naturales que sirvieron para acumulación originaria impulsada por Europa.

La importancia de las élites burguesas y oligárquicas latinoamericanas al profundizar la modernización económica y liberar de ataduras al capital contribuyó centralmente a la configuración de relaciones sociales de producción en función de lo externo más que de lo interno, estructurando así economías productoras de materias primas. Por tanto, la lógica de control y dominio de los países centrales sobre los periféricos en complicidad con las élites burguesasoligárquicas son parte del funcionamiento del modo de producción capitalista en el que la ganancia de unos es la condena de otros.

Comprender tal situación permite una aproximación más completa al tema, dado que se integran al análisis elementos históricos; un procedimiento distinto omitiría una parte esencial para entender lo que ocurre actualmente, a sabiendas de que la historia latinoamericana es compleja y más amplia.

En las últimas décadas, la configuración espacial del campo latinoamericano se ha revolucionado con la emergencia del fenómeno denominado agronegocio. Impulsado desde afuera, se trata de una medida impositiva que viene desde los Estados Unidos y que, según las condiciones propias de cada país, ha adquirido una diferente profundidad. El desarrollo e implantación del agronegocio ha agudizado aún más las formas de apropiación del capital sobre los bienes de la naturaleza, aumentando así las tasas de extracción de las materias primas. Si se observan datos de la FAO (2015) y la CEPAL (2015), al comenzar el siglo XXI se ha registrado una fuerte modificación de la estructura agraria en el este sudamericano, lo que es producto de la desbocada expansión de la frontera agrícola y ha traído diversas transformaciones territoriales. Es una vasta región conformada por Paraguay, Uruguay, el centro-norte de Argentina, el este de Bolivia y el noreste, centro-oeste y sur de Brasil, y se caracteriza por ser la

1 Este artículo forma parte de mi tesis doctoral Los territorios agrarios: reconfiguración de las transformaciones territoriales durante el comienzo del siglo XXI en el Uruguay. 
principal productora de cereales de secano del mundo (trigo, soja, maíz, sorgo, cebada), la segunda en ganado vacuno, la tercera en producción de leche y la cuarta en silvicultura (FAO, 2015), ${ }^{2}$ además de contar con monocultivos para biocombustibles como la cańa de azúcar y la palma aceitera (sobre todo en Brasil). Este perfil de producción la ubica en Latinoamérica y en el resto del planeta como una región de gran relevancia alimentaria. Durante los últimos cinco ańos, en los países involucrados se aprecia un crecimiento en a) exportaciones de bienes primarios, b) índice de concentración de la tierra (Gini), c) inversión extranjera directa, $d$ ) superficie de silvicultura, e) superficie agrícola, $f$ ) superficie de tierras arables, $g$ ) superficie regada, $h$ ) uso de fertilizantes y plaguicidas, y i) una disminución de los bosques naturales (CEPAL, 2015). Estos datos, aunque genéricos, evidencian cómo en esta región se ha intensificado la producción agropecuaria con la base de las políticas agrarias y económicas de los países que la conforman y el movimiento mundial de capitales, mismos han encontrado un espacio fértil para la acumulación.

Esta región se enfrenta a una situación singular en la historia en el que el modelo del agronegocio es central pero no único. Por esto importa sistematizar y analizar cómo se configuró dicho modelo, a fin de contribuir al debate teórico y empírico sobre su crecimiento en el espacio latinoamericano. En este sentido, el presente artículo analiza los principales elementos del modelo del agronegocio en Latinoamérica, desde sus orígenes y su implementación, hasta la actualidad, pero enfocándose particularmente en Uruguay, país que reúne muchos de los rasgos característicos del modelo.

Con ese fin el artículo se divide en cuatro apartados. El primero revisa los antecedentes del modelo del agronegocio, destacando su origen y expansión en América Latina. El segundo se asocia al contexto histórico del capitalismo, el cual generó las condiciones materiales para el desarrollo del modelo. El tercero remite a sus más importantes características de organización y funcionamiento y cómo todo lo precedente se conjuga en el particular espacio agrario uruguayo. Para terminar, se exponen los principales hallazgos del estudio.

\section{Los antecedentes del agronegocio: origen y expansión en Latinoamérica}

A finales de la década de 1960, en el marco de la expansión del capital en el mundo, se impulsó una forma de organización del capital en el espacio agrario

2 Se realizó un análisis comparativo para el periodo 1983-2013, perteneciente a los países más importantes en la producción alimentaria global: Argentina, Australia, Bolivia, Brasil, China, Estados Unidos, India, Nueva Zelanda, Paraguay y Uruguay. 
cuya función sería reestructurar las relaciones de producción dominantes a través de lo que, a iniciativa de la Escuela de Administración y Negocios de la Universidad de Harvard (Estados Unidos), se denominó agronegocio. Davis y Goldberg definieron este término como "el total de operaciones que integran la producción de manufacturas y su distribución; producción en las fincas; el almacenamiento, procesamiento y distribución de las materias primas agrícolas y artículos producidos a partir de ellas" (Davis \& Goldberg, 1957: p. 2. Traducción propia). ${ }^{3}$ Ellos partían de la premisa de que el campo pasaba por profundas transformaciones productivas que derivaban de la revolución tecnológica impulsada a raíz de la Segunda Guerra Mundial; el progreso científico podía utilizarse en la agricultura como fórmula para solucionar los desajustes y desequilibrios en un proceso evolutivo. El principal cambio, señalaban, consistía en que las fincas dejaban el modelo de la autosubsistencia para pasar a la función comercial por medio de la producción del monocultivo. Actividades como el almacenamiento, procesamiento y distribución de los productos se transferían a empresas que fabricaban productos industriales como tractores, camiones, combustibles, fertilizantes y agroquímicos, entre otros (Davis \& Goldberg, 1957). De esta forma, cada eslabón de la cadena realizaría la mayor parte de sus negocios con los eslabones que le preceden y le siguen. Por tanto, el productor superaría la dicotomía agricultura/industria buscando su integración vertical y horizontal a manera de cadena de valor, tomando al consumidor como punto de partida (Gras \& Hernández, 2013).

La influencia de Davis y Goldberg traspasó el ámbito académico y se diseminó entre los que tomaban decisiones en la política agrícola estadounidense, a tal grado que Davis recibió el cargo de viceministro de Agricultura para el segundo periodo presidencial de Eisenhower (1957-1961).

Para el caso del modelo del agronegocio en América Latina existen dos referencias fundamentales: 1) Agribusiness Management for Developing Countries-Latin America (Gestión de agronegocios para el desarrollo de paises de Latinoamérica) de Ray Goldberg, la cual, publicada en 1974, tenía como objetivo aportar una base conceptual para la producción de las materias primas que formaban parte del agronegocio en América Central, y destacar su papel en esta región y potencial para satisfacer las necesidades de consumo estadounidenses . 2) Agribusiness in Latin America (Agronegocio en Latinoamérica) de James Austin, también de 1974 y donde el autor, influido por Goldberg, señalaba que el agronegocio debía funcionar más como un sistema integrado por em-

3 En el original, "agribusiness means the sum total of all operations involved in the manufacture and distribution of farm supplies; production operations on the farm; and the storage, processing, and distribution of farm commodities and items made from them". 
presas de transporte, almacenamiento, comercialización y financiamiento. Ya desde entonces se apuntaba la importancia de la Latin American Agribusiness Development Corporation (Corporación Latinoamericana para el Desarrollo del Agronegocio) (LAAD, por su sigla en inglés), institución que, fundada en 1969, tenía por propósito difundir el agronegocio en América Latina (Austin, 1974) y se componía de más de diez empresas ${ }^{4}$ que recibían el apoyo del Estado y que aún mantienen su presencia en doce países latinoamericanos. Desde su fundación la LAAD trabajó de modo ininterrumpido para incorporar el agronegocio a América Latina, pero también para impedir el desarrollo de otros modelos, principalmente de aquellos que pretendían modificar el régimen de tenencia de la tierra a favor de los pequeños productores. Según Roos (2000), presidente de la LAAD entre 1972 y 1998: "la producción agrícola quedó estancada debido a que los agricultores eficientes fueron desplazados de sus tierras y reemplazados por agricultores pobres e ineficientes. Estos nuevos agricultores fueron acostumbrados a producir para sus propias familias y no para el mercado. Ellos son analfabetos e incapaces de aprender nuevas tecnologías" (Ross, 2000: p. 14).

Este impulso del agronegocio se fue tejiendo en el espacio agrario latinoamericano con la complicidad e interés propios de organismos regionales como el Instituto Interamericano de Cooperación para la Agricultura (IICA), que definía a tal concepto como "Un sistema integrado de negocios enfocado en el consumidor, que incluye los aspectos de producción primaria, procesamiento, transformación y todas las actividades de almacenamiento, distribución y comercialización, así como los servicios, públicos y privados, que son necesarios para que las empresas del sector operen competitivamente." (IICA, 2010: p. 6).

Según este organismo multilateral, los agronegocios se sustentan en negocios económicos que se enfocan al consumidor con base en un sistema de cadenas de valor y no solo se ocupan de productos alimenticios sino de todas las dimensiones de la agricultura, lo que abre la puerta a los agrocombustibles o a la silvicultura, entre otros. Es una visión que responde a promover la agricultura comercial con base en la acumulación y reproducción del capital, en vez de estimular otras formas de agricultura como, por ejemplo, el autoconsumo.

Una vez que el agronegocio se comenzó a expandir por todo el continente, en la academia se comenzó a estudiar el tema desde diversas posiciones teóricas.

Los tratamientos más críticos se inspiraron en el pensamiento marxista. Es el caso de la corriente de la cuestión agraria, la cual se integra de dos tendencias;

4 Se trata de Bank of America, Good Year, Cargill, International Finance Coporporation, John Deere, J. P. Morgan, Deutsche Investitions, Monsanto, Dole Food Company, Rabobank, Gerber y Unilever. Recuperado en noviembre de 2016, de http://laadsa.com/spanish/who_we_are/Share_Holders.asp 
por una parte, la que entiende como hegemónicas las relaciones capitalistas en el desarrollo de la agricultura, las cuales llevarían a eliminar las relaciones nocapitalistas e introducen el trabajo asalariado (proletarización), como la clase social que llevará hacia la revolución y a la superación del sistema capitalista. Por la otra, la corriente que también entiende como hegemónicas las relaciones capitalistas, pero no solo acepta la proletarización como camino emancipador sino que agrega al campesinado (Felicio, 2011; Fernandes, 2013). Dentro de esta corriente caben otros dos abordajes: uno, inspirado también en el marxismo, coincide con los anteriores respecto al cambio sobre los medios de producción, aunque sostiene que no basta con dicha función, sino que se debería transitar hacia la ruptura de las relaciones sociales cosificadas que articulan históricamente los actos entre los sujetos, en donde la liberación de la enajenación histórica sería un camino central y necesario. En esta vertiente destacan Calderón (2006), León (2011) y Oliveros (2014), entre otros. Un segundo abordaje estaría inspirado en el anarquismo, que también busca la superación del capitalismo, pero desde una democratización del poder y de las jerarquías impuestas por el Estado, en este caso, el proceso de autonomías y autogestión de herramientas ayudarían a producir un espacio contrahegemónico (Marcos, 1998; Felici, 1996; Neto, 1996; Piccolo, 2009).

Por otro lado estarían los abordajes acríticos de corte más liberal, los cuales, situados en la corriente del capitalismo agrario, se han inspirado en los fundadores del modelo del agronegocio. En este abordaje se afirma que el desarrollo del espacio agrario basado en la producción de materias primas establece una competitividad que favorece la modernización y progreso del campo, pues se basa en la innovación permanente y en la aplicación de tecnología de vanguardia, lo que aumenta los niveles de productividad. Dentro de esta corriente se inscribe un enfoque de corte funcionalista que identifica el papel y rol de la agricultura familiar o del campesinado en el conjunto del funcionamiento del capitalismo agrario, y defiende que estos deben adaptarse al desarrollo del sistema capitalista, buscando nichos de mercados distintos a los de la agricultura convencional de gran escala (Felicio, 2011).

Hasta aquí se han descrito los impulsores del modelo, los organismos regionales y la academia en general. Toca el turno de las organizaciones sociales, las cuales presentan dos diferentes posiciones frente al agronegocio: las críticas y las acríticas.

En relación a los críticos, destacan los movimientos sociales que defienden su territorio y disputan la tierra frente al agronegocio; son sujetos claves en la construcción de alternativas productivas a través de prácticas basadas en la agricultura orgánica. El principal movimiento internacional que resiste contra el gran capital es La Vía Campesina, una agrupación que aglutina a millones de 
campesinos, pequeños y medianos productores, pueblos sin tierra, indígenas, migrantes y trabajadores agrícolas de todo el mundo y que defiende la práctica de la agricultura sostenible a pequeña escala para promover la justicia social y la dignidad. Reivindican asimismo la soberanía alimentaria como un horizonte de transformación de la estructura agraria actual (La Vía Campesina, 2017).

En la dirección acrítica aparece un conjunto diverso y fragmentado de agrupaciones de productores medianas y grandes que están a favor del agronegocio, al que operan en asociación con las élites políticas nacionales. Un ejemplo es la Federación de Asociaciones Rurales del Mercosur (FARM), la cual promueve la integración regional del sector y la mejora permanente de la competitividad de la cadena agropecuaria (FARM, 2017). Los miembros de esta asociación proceden del Grupo Cairns, un conjunto de países exportadores de productos agrícolas que impulsan políticas de liberalización de los mercados. Por su parte, la Federación Centroamericana de Cámaras Agropecuarias y Agroindustriales (Fecagro) igualmente fomenta políticas a favor de la competitividad de los sectores, junto al intercambio de información científica, tecnológica y comercial, acorde a los intereses del gremio agro-empresarial (Fecagro, 2017).

Del panorama de cómo se han ido tejiendo las posturas teóricas y prácticas y de los principales actores del agronegocio en América Latina vale rescatar que el modelo no se originó en esta región, sino que por distintas estrategias se fue implantando como respuesta a la correlación de fuerzas internas. Es importante resaltar el papel de las universidades en este proceso, dado que son grandes promotoras del financiamiento para la producción teórica y empírica por lo que de este modo son funcionales a la expansión del agronegocio. Para comprender mejor el funcionamiento del agronegocio es necesario detenerse en el contexto del capitalismo latinoamericano que ha sido sustento de dicha implementación.

\section{Algunos elementos del capital que han contribuido a la consolidación del agronegocio}

Como ha ocurrido en muchos casos, las estrategias del capital para ajustar el patrón de acumulación mundial, se establecen mediante políticas estructurales que se desarrollan en un contexto histórico determinado, en el caso del agronegocio, este fue el de la posguerra. El excedente tecnológico-militar que se produjo entonces reactivó el sector agroproductivo y agroindustrial aumentando la productividad con el fin de incrementar la acumulación del capital (Perkins, 1997). Este mecanismo, denominado revolución verde, nace en Estados Unidos y consiste en la introducción de variedades de alto rendimiento, principalmente de trigo y arroz, junto con la aplicación de fertilizantes y agroquímicos para 
mantener esa mejora de los cultivos (Griffin, 1982). La revolución verde ha sido un pilar de la expansión del agronegocio en Latinoamérica.

Uno de los objetivos de la revolución verde es dotar a los países "subdesarrollados" de paquetes tecnológicos dependientes, un mecanismo armado y diseñado que involucra a las instituciones del gobierno, a las universidades y a las empresas transnacionales encargadas de implementar en campo los programas.

Según los impulsores, el desarrollo de la revolución verde llegaba para facilitar el aumento de la producción mundial de materias primas con lo que se reactivaba la economía global luego de una profunda guerra y crisis de acumulación (Arnon, 1987).

Este proceso comandado por las corporaciones estadounidenses se materializó por medio de la expansión de sus capitales por el mundo, lo cual llevó al desembarco de estos en diversas ramas de la economía latinoamericana. En 1945 existían 182 subsidiarias estadounidenses en América Latina, en 1955 ya eran 357 y para 1965 alcanzaron las 888 empresas y una inversión de 2741 millones de dólares (Cueva, 1979).

Esta coyuntura se mantuvo hasta principios de los años setenta, cuando los indicadores macroeconómicos de las economías latinoamericanas comenzaron a mostrar fuertes indicios de desaceleramiento, principalmente por la diferencia de los términos de intercambio. Para entonces ya había pasado la reactivación de Europa a través del Plan Marshall, ${ }^{5}$ lo que había incrementado la producción mundial que luego condujo a la sobreacumulación del capital global que llevaría a una contracción de la economía. Tal situación sentó la base para el comienzo de un periodo de deterioro y crisis recurrentes del modo de producción capitalista que rige hasta nuestros días. Entre las primeras medidas impulsadas por Estados Unidos para reactivar la economía mundial, y en especial la de ellos, fue el abandono del patrón oro establecido en los acuerdos de Bretton Woods, los cuales habían determinado que todas las monedas del mundo estarían vinculadas al dólar, y este, a su vez, estaría atado al oro, es decir, que los dólares serían intercambiables por oro a una tasa fija (Brunhoff, 1978). Esta medida aumentaría la hegemonía económica de Estados Unidos en el mundo, ya que de este modo imponía su moneda al conjunto de transacciones económicas entre los países, acrecentando el peso del sector financiero sobre las demás ramas de la economía mundial. Esta herramienta de financiación ayudó a que durante la década de los ochenta se diera un incremento sostenido de producción y exportaciones agrarias. Es a partir de esta fecha que

5 Fue un apoyo económico de Estados Unidos para la reconstrucción de Europa luego de la Segunda Guerra Mundial, lo cual tenía como objetivo reactivar la economía mundial capitalista y evitar el avance de la URRS. 
inició una política feroz de acuerdos de libre comercio con distintos países en todo el mundo. El objetivo era mantener el control de los stocks mundiales para manejar los precios internacionales de los productos, fomentando la exportación en periodos de conveniencia de precios y promoviendo el dumping ${ }^{6}$ entre otros países (Burbach \& Flynn, 1980). A su vez, el gobierno estadounidense, con la Public Law 480, permitió que los productos exportables, sobre todo los granos, fuesen adquiridos en monedas locales por los países importadores por intermedio de un crédito subsidiado por el Estado (Burbach \& Flynn, 1980). Estas medidas favorecieron la expansión del agronegocio de las empresas estadounidenses desestimulando la producción local agropecuaria y fueron los granos el sector de mayor crecimiento, lo que devino en la profundización de la dependencia económica de los países vendedores y se favoreció a los productores de Estados Unidos. Este proceso ayudó a que los países latinoamericanos aumentaran su gasto público y creciera su deuda respecto de los países centrales (Chesnais, 2005). Al mismo tiempo, con tales medidas se redujeron los costos laborales y se facilitó el avance de la mundialización del capital y la instalación del gran capital transnacional.

En este contexto, en la década de los noventa el capitalismo alcanzó su etapa más profunda, la del neoliberalismo, el cual se caracteriza por implementar una política económica estructural permanente que implementa la apertura comercial de la economía nacional, utiliza la rebaja de aranceles, elimina impuestos a las importaciones y exportaciones y se sustenta en una mínima intervención del Estado en el mercado. También consiste en una postura ideológica que defiende el establecimiento de prácticas que logren la mejor forma de bienestar humano mediante la emancipación de las libertades y las destrezas empresariales individuales dentro de un marco institucional en el que predominen sólidos derechos de propiedad privada y mercados libres. Se trata de un proyecto de la burguesía para restablecer su poder de clase disminuido en la posguerra con el keynesianismo, por cuanto este había conferido un mayor poder adquisitivo a las clases obreras en esa época llamada también fordismo (Harvey, 2005).

Los impulsores de tal modelo económico argumentaban que la liberalización de los mercados interno y externo más la eliminación de los subsidios estatales para el sector agropecuario generarían el crecimiento de este con la consecuente reducción de la deuda fiscal. Esto hizo crecer el volumen de las exportacio-

6 El dumping se refiere a una práctica comercial basada en establecer diferencia de precios de un mismo producto. Consiste en venderlo por debajo del costo de producción en el mercado exterior, afectando así al resto de los productos (омc, 2015). 
nes pero también llevó a una pérdida permanente del precio de los productos exportables y al incremento sostenido de las importaciones (Dirven, 1999).

Las consecuencias del modelo fueron la reducción de los salarios y el aumento incesante del desempleo, lo que unido al crecimiento de la inflación disminuyó el poder de compra de los trabajadores. Y como la cuota de explotación se elevó por los bajos salarios, hubo un sobrante de capital que encontró escasas condiciones rentables de inversión productiva por lo que migró a la esfera financiera. Este tipo de capitales comenzó a predominar en la economía global e impuso altas tasas de interés que invadieron la ganancia industrial y agrícola, lo que originó un círculo vicioso, ya que la inversión productiva disminuía aún más y se intensificaba con ello el predominio del capital financiero sobre el productivo (Rubio, 2012).

Durante este periodo ocurrió un fenómeno particular: por un lado, las derivaciones del aumento de las tasas de interés de la Reserva Federal estadounidense que implementó Paul Volcker en 1979 dieron pie a que los bancos lideraran la ofensiva global del capital frente al trabajo e impusieran nuevas pautas de disciplina en las actividades económicas (Marichal, 2010); por otro, se introdujo la desregularización casi total del financiamiento de la agricultura mundial, lo que flexibilizó el mercado financiero de los productos agrarios mediante el índice de materias primas Goldman Sachs ${ }^{7}$ compuesto de 24 productos primarios (Vergopoulos, 2014).

Esta situación hizo que aparecieran distintas estrategias financieras para lograr una mayor desregularización de la fase productiva. Entre los actores principales se cuentan los fondos de inversión, instituciones de ahorro sin personalidad jurídica que manejan capitales variables de distintos patrimonios, divididos en partes iguales, lo que las diferencia de la inversión de capital fijo (Castillo, 2012). Estos fondos, a diferencia del capital fijo, pueden modificar sus patrimonios sin cumplir con regímenes burocráticos y devolver el capital invertido en cuanto lo deseen los inversionistas, lo que produce las condiciones para un mayor movimiento de flujo de capitales de una rama productiva a otra o de una región del planeta a otra (Castillo, 2012). Muchos fondos de inversión se instalan en los llamados paraísos fiscales, espacios financieros a los que llegan para evadir la retención de impuestos y la declaración del origen del capital; en otras palabras, evitan así cualquier regulación y declaración de información que los afecte (Cattani, 2009). Esta regularización ha provocado el incremento de la especulación y volatilidad de los capitales, una mayor interconexión del sistema de capitales globales y el control por parte de los Estados nación.

7 El nombre original fue Goldman Sachs Commodity Index (GSCI) y se sustituyó por el actual S\&P GSCI, debido a que lo adquirió la financiera transnacional Standard \& Poor's. 
Es en este contexto, que el modelo del agronegocio se consolida y encuentra terreno fértil para su permanente propagación, evidenciándose en Latinoamérica un número creciente de empresas transnacionales en el sector agrario (UNCTAD, 2009).

\section{Las principales características del agronegocio}

El agronegocio se caracteriza en primer lugar por comportar una lógica de concentración empresarial que vincula distintos sectores de la cadena agroindustrial. De este modo se conforman clústers que suponen nuevas formas de gestión por parte de los actores involucrados (Gras \& Hernández, 2013) y alianzas entre empresas para producir tecnologías en las que la innovación es un pilar del modelo, mismo que ha sido desplazado a la investigación en instituciones públicas. Otro rasgo del agronegocio se vincula a su base productiva, la cual se orienta a los monocultivos, lo que reduce la diversidad biológica y configura enormes superficies para ese uso. Así, surgen productores que gestionan grandes extensiones de cultivos, se expulsa al pequeño productor (familiar o campesino) y se reconvierte a los que resisten al modelo (Arbeletche \& Gutiérrez, 2010). Finalmente, el agronegocio se distingue por la mayor acumulación de capital mediante el acaparamiento de tierras, lo que lo hace distinto de otros momentos del capitalismo agrario. Esto último sucede en otras partes, por ejemplo, en África subsahariana. Lo distinto en América Latina es que se trata de un hecho extrarregional e intrarregional que se observa en empresas (trans) latinoamericanas que se nutren de la extranjerización y alta concentración de la tierra (Borras et al., 2012). Son empresas con un vínculo directo con el exterior, pero, en muchos casos, los capitales son regionales, como ocurre en Bolivia, Paraguay y Uruguay con la llegada de capitales argentinos o brasileños (FAO, 2011).

Dichas megaempresas buscan su expansión intrarregional disminuyendo los riegos que ponen en jaque la acumulación de capital. Por eso es que pretenden la diversificación biofísica (clima, suelos), político-institucional (estabilidad democrática) y monetario-financiera (estabilidad económica). Esta estrategia puede ejemplificarse con las empresas transnacionales de la silvicultura, las cuales analizan globalmente las ventajas comparativas de un conjunto de países, entre estos, Argentina, Brasil y Uruguay (Cubbage et al., 2010).

El avance de la innovación y la tecnología es central para el agronegocio, cuya visión es ajustar los ciclos naturales a los del capital para acelerar los tiempos biológicos y aumentar así la eficiencia de la productividad primaria neta. De esta forma busca la transferencia eficaz entre las cadenas tróficas perdiendo 
menos energía por unidad de tiempo y superficie (Leff, 1994). Estos procesos se observan en la producción de soja, maíz, algodón y canola mediante la transgénesis como elemento estructurador del paquete tecnológico.

Otro pilar del agronegocio es que reconfigura las relaciones entre los sujetos con lo que reestructura los sectores dominantes confrontando así a las antiguas oligarquías terratenientes; de este modo obliga a los grandes productores agropecuarios a reconvertirse a la nueva lógica del capital o a aceptar la pérdida de su liderazgo. Con ello ha emergido una renovada división social del trabajo agrario entre las naciones del Sur y del Norte (Gras \& Hernández, 2013).

En los casos argentino y uruguayo este modelo tuvo la singularidad de que existían formas empresariales cuya estrategia estaba asociada a una red de operaciones agroproductivas basadas en diversos mecanismos de capitalización. Diferenciándose de la forma tradicional de la producción en la región, asociada a grandes propietarios y a valorar la tierra como patrimonio y no como factor productivo, esta nueva estrategia consiste en lograr una mayor eficiencia productiva mediante la rotación del capital, transformándolo de fijo en variable e intensificando la tercerización de labores; se trata de un contexto en el que el conocimiento es un factor central pues constituye un capital que optimiza la coordinación de las tareas (Hernández, 2007). Esta forma productiva emergente con los nuevos actores en el espacio agrario y la reconfiguración de los existentes, ha establecido finalmente el modelo agroempresarial (Gras \& Hernández, 2013).

Entre los actuales sujetos del agronegocio se fundan singulares formas de gestión en la administración de los capitales. Es el caso del pool de siembra que se financia con fondos de inversión asociados a bienes y servicios que pertenecen a actores del sector agropecuario y ajenos a este. El objetivo es emprender actividad agrícola durante un periodo determinado (lo más frecuente es por un año) con la meta de obtener el mayor beneficio económico. En su mayoría son capitales variables externos (no son propietarios de las tierras ni de las maquinarias), con una gestión financiera, económica, comercial y agronómica muy profesional (Grosso et al., 2010).

Acompañando a tales formas de intervención en el espacio agrario, se instala la ideologización del territorio (Fernandes, 2013) con las fundaciones de responsabilidad social empresarial (RSE), cuyo fin es apoyar el financiamiento de organizaciones civiles locales. Asimismo se conforman alianzas con las instituciones públicas para financiar algún proyecto puntual en educación, salud o seguridad (Gras \& Hernández, 2013).

En definitiva, los fenómenos descritos y ocurridos en las últimas dos décadas han reconfigurado el espacio agrario latinoamericano. Y si bien han sucedido con diferencia entre países, han dejado consecuencias históricas con procesos 
exponenciales de privatización y concentración de la tierra, disminución de los trabajadores y población rurales, e impactos que afectan al medio ambiente y a los recursos naturales (Carrasco, Sánchez \& Tamango, 2012; Olarte, 2012).

\section{El agronegocio en Uruguay: una aproximación empírica}

La inyección masiva de capitales en el espacio agrario fue evidente en el incremento de la inversión extranjera directa (IED) que recibió Uruguay: en 2002 registró 194 millones de dólares que en 2015 se incrementan a 1647, con un acumulado para dicho periodo de 22442 millones de dólares (CEPAL, 2016). De tal cifra, el sector "Agricultura, ganadería, caza y silvicultura" recibió en ese momento 3656 millones, esto es, el 16.2\% (Uruguay XXI, 2016b). Esta inversión repercutió y presionó para un encarecimiento sostenido del precio de la tierra, la cual pasó de 725 dólares la hectárea promedio en 2005, a 3584 dólares en 2015. Un incremento de casi 400\% (DIEA, 2016).

Para ver la configuración interna de los sectores productivos y su relación con el modelo del agronegocio, se han elaborado las tablas 1-6 y el anexo 1, donde se muestra el peso de los capitales transnacionales en el espacio agrario uruguayo. Allí es posible observar que de los sectores productivos que podrían cumplir las características del agronegocio destacan la ganadería, la lechería, la agricultura de regadío (arroz), la agricultura de secano (soja, trigo y maíz), la silvicultura y la fruticultura. Con ese propósito es que se identifica el nombre del capital —empresas, grupos de empresas o fondos de inversión—, dónde opera geográficamente y su probable origen. Este último elemento es difícil de verificar ya que en general se oculta esta información para evadir impuestos, lo que a su vez impide un mayor control por parte del Estado, una situación que se profundiza con los fondos de inversión. También se ha considerado el tiempo de operación del capital, refiriendo el año de inicio de operaciones en Uruguay. Cuando la empresa ya funcionaba y fue adquirida por un nuevo capital, se consideró este momento como su origen. Desde luego, hay casos en los que son nuevos los capitales y nuevas las empresas. Lo importante es destacar en qué periodo se establecen y fusionan los capitales. De igual forma se relacionó el aporte del capital transnacional al total de las exportaciones de 2015, con lo que se obtuvo su magnitud en los diversos sectores agrarios.

Tales datos fueron relacionados a la conceptualización de Fernandes \& Welch (2008), autores afines a la corriente campesinista de la cuestión agraria, en la cual el agronegocio se entiende como un complejo sistema integrado por las fases agropecuaria, industrial, mercantil, financiera, tecnológica e ideológica. Fue así que se elaboraron las fases del agronegocio identificando, mediante un análisis 
sistemático, cómo el capital se define y se muestra hacia afuera. ${ }^{8}$ En tanto que a partir de un criterio cualitativo (presencia o ausencia) se construyeron las tablas para las distintas fases. Respecto a las fases agropecuaria-productiva, industrial y mercantil, se analizó si el capital interviene en todas o si su objetivo es solo una; en definitiva, se buscó identificar el objetivo de la acumulación que presenta el capital. Para la fase financiera se identificó si el capital incluía en su arquitectura una rama de este tipo a través de su cotización en bolsas de valores nacionales o internacionales o mediante una política de estímulo para la captación de nuevo capital vía los fondos de inversión. Por su parte, la fase ideológica refiere a si el capital muestra una política directa por medio de la RSE para presumirse como un aporte a la comunidad buscando incidir así en el territorio. Todos los capitales referidos provienen de la revisión y actualización de los trabajos de REDES-AT (2012), Rulli, Savior \& D'Odorico (2012), Oyhantçabal et al. (2014), LAND MATRIX (2016) y Florit \& Piedracueva (2017).

Para una mejor comprensión de las tablas 1-6, la descripción y discusión de los resultados se realizará por sectores agrarios.

En primer lugar, en el sector cárnico (tabla 1) se observa alta concentración de capital extranjero — sobre todo en la rama industrial—, con mayor presencia de capitales brasileños que representan el $43.2 \%$ del total de las exportaciones del sector. También se evidencian los capitales asiáticos (China y Japón), instalados muy recientemente, en particular el japonés que adquirió Breeders \& Packers Uruguay, el más importante frigorífico del país tanto en exportaciones como en cantidad de faena anual (INAC, 2017). Por otro lado, el fondo de inversión Union Agriculture Group es la principal empresa agropecuaria uruguaya con más 85000 hectáreas gestionadas, tanto en la ganadería como en la agricultura, mostrándose así como una empresa de alta rentabilidad para el inversor, que opera desde las Islas Vírgenes británicas (un paraíso fiscal).

Respecto a las fases del agronegocio, existen cuatro grupos de capital con fuerte presencia en la mayoría de ellas, todos buscando controlar la cadena de valor. En los más de los casos, el capital más importante se concentra en la fase industrial y mercantil con un aporte de alrededor del 36\% del total del sector, pero concentrando $14.3 \%$ de exportaciones uruguayas en 2015 (Uruguay Xxi, 2016a).

En cuanto a la fase financiera, la mayoría de estos capitales cotizan en bolsa de valores participando con acciones ${ }^{9}$ o mercado de contratos hechos a medi-

8 Este análisis se realizó con la información que proporcionan las empresas en sus páginas web.

9 Mecanismo con el cual un capital divide en fracciones iguales su patrimonio y lo pone a la venta para obtener nuevos ingresos y reinvertirlos en su reproducción; cada fracción se conoce como acción. El órgano para las transacciones monetarias de compra-venta de acciones se denomina bolsa de valores. 
da. ${ }^{10}$ Mientras que en relación a la fase tecnológica la distribución es pareja, ya que los capitales de mayor peso se muestran como vanguardia en la aplicación de tecnología durante el proceso industrial, mientras que el resto no refieren a esta fase. Cabe resaltar que los tres grupos industriales de mayor envergadura han hecho una fuerte inversión en la fase ideológica declarándose RSE. De esta manera han invertido en educación: escuelas públicas rurales, universidades públicas y privadas, ministerios y/o institutos y asociaciones de productores, y en programas destinados a la educación vial, el deporte y la promoción del empleo.

Tabla 1. Capital transnacional en el sector cárnico y su vinculación con las fases del agronegocio (Uruguay)

\begin{tabular}{|c|c|c|c|c|c|c|c|c|c|c|}
\hline \multirow[t]{2}{*}{$\begin{array}{l}\text { Sector } \\
\text { agrario }\end{array}$} & \multicolumn{4}{|c|}{ Capital } & \multicolumn{6}{|c|}{$\begin{array}{l}\text { Fases del agronegocio } \\
\text { (presencia o ausencia) }\end{array}$} \\
\hline & Nombre $^{1}$ & $\begin{array}{l}\text { Origen } \\
\text { (país) }\end{array}$ & $\begin{array}{l}\text { Comienzo de } \\
\text { operación en } \\
\text { Uruguay (año)** }\end{array}$ & $\begin{array}{l}\text { Participación en el } \\
\text { sector (\% exporta- } \\
\text { ción en 2015) }\end{array}$ & Po $(h a)^{1}$ & In & Me & $\mathrm{Fi}$ & $T e$ & Id \\
\hline \multirow{8}{*}{ 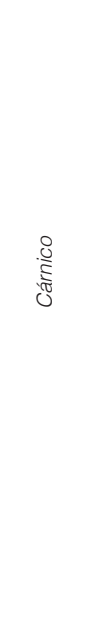 } & $\begin{array}{l}\text { Grupo } \\
\text { Marfrig }\end{array}$ & Brasil & 2006 & 23.3 & $\sqrt{ }(644)$ & $\sqrt{ }$ & $\sqrt{ }$ & $\sqrt{ }$ & $\sqrt{ }$ & $\sqrt{ }$ \\
\hline & $\begin{array}{l}\text { Grupo Miner- } \\
\text { va Foods }\end{array}$ & Brasil & 2011 & 19.9 & $x$ & $\sqrt{ }$ & $\sqrt{ }$ & $\sqrt{ }$ & $\sqrt{ }$ & $\sqrt{ }$ \\
\hline & $\begin{array}{l}\text { Nipponham } \\
\text { Group }\end{array}$ & Japón & 2017 & 9.1 & $x$ & $\sqrt{ }$ & $\sqrt{ }$ & $\sqrt{ }$ & $\sqrt{ }$ & $\sqrt{ }$ \\
\hline & $\begin{array}{l}\text { Hijazi \& } \\
\text { Ghosheh } \\
\text { Group }\end{array}$ & Jordania & 2003 & 5.6 & $x$ & $\sqrt{ }$ & $\sqrt{ }$ & $\sqrt{ }$ & $x$ & $x$ \\
\hline & $\begin{array}{l}\text { Heilongjiang } \\
\text { Foresun } \\
\text { Agriculture } \\
\text { Group }\end{array}$ & China & 2015 & 4.6 & $x$ & $\sqrt{ }$ & $\sqrt{ }$ & $\sqrt{ }$ & $x$ & $x$ \\
\hline & Eurofrance & Francia & 2010 & 1.6 & $x$ & $x$ & $\sqrt{ }$ & $x$ & $x$ & $x$ \\
\hline & $\begin{array}{l}\text { Resto de } \\
\text { empresas } \\
\text { uruguayas }\end{array}$ & Uruguay & & 35.9 & & & & & & \\
\hline & $\begin{array}{l}\text { Union } \\
\text { Agriculture } \\
\text { Group }\end{array}$ & $\begin{array}{l}\text { Islas } \\
\text { Vírgenes } \\
\text { (Fondos de } \\
\text { inversión) }\end{array}$ & 2008 & & $\sqrt{ }(126800)^{*}$ & $x$ & $\sqrt{ }$ & $\sqrt{ }$ & $x$ & $x$ \\
\hline
\end{tabular}

Notas: *Información total de hectáreas propias (35000) y arrendadas (94800) en Uruguay; no discrimina por sector agrario. ${ }^{* *}$ Refiere al año de compra del grupo corporativo en el mundo y por ende el comienzo en Uruguay.

Fases del agronegocio: Po: Productiva, In: Industrial, Me: Mercantil, Fi: Financiera, Te: Tecnológica, Id: Ideológica. Fuente: Elaboración propia con base en ${ }^{1}$ páginas web de las empresas; ${ }^{2}$ Uruguay XXI (2016).

En cuanto al sector lechero (tabla 2), la situación es muy diferente debido a que la mayor empresa exportadora del país durante los últimos diez años,

10 Mejor conocido como over-the-counter, son contratos entre capitales a medida de su conveniencia, en los que se pauta el plazo de compra y venta, el monto fijado y el volumen de transacciones posibles de realizar. 
la Cooperativa Nacional de Productores de Leche (Conaprole), es de capital uruguayo (Uruguay xxI, 2016a). Por ello en este sector hay baja presencia de capitales extranjeros con fuerte inversión en los últimos cinco años. De los cuatro grupos, dos controlan toda la cadena de valor (Grupo Bulgheroni y Nestlé Dairy Partners Americas) y el resto se enfoca a la fase industrial y mercantil (Grupo Lactalis) y exclusivamente productiva (Olam International Limited). Así, se observa una fuerte presencia en las fases industrial y mercantil, en menor medida en lo financiero y tecnológico, y casi nula en programas vinculados a la RSE. Merece un destaque la fase tecnológica, ya que ha habido un aumento sustancial de la productividad debido a que las empresas invierten para mejorarla por hectárea, lo que ha permitido un creciente volumen de exportaciones en detrimento de la disminución de la superficie y del número de vacas.

Tabla 2. Capital transnacional en el sector lechero y su vinculación con las fases del agronegocio (Uruguay)

\begin{tabular}{|c|c|c|c|c|c|c|c|c|c|c|}
\hline \multirow[t]{2}{*}{$\begin{array}{l}\text { Sector } \\
\text { agrario }\end{array}$} & \multicolumn{4}{|c|}{ Capital } & \multicolumn{6}{|c|}{$\begin{array}{l}\text { Fases del agronegocio } \\
\text { (presencia o ausencia) }\end{array}$} \\
\hline & Nombre ${ }^{1}$ & $\begin{array}{l}\text { Origen } \\
{\text { (país })^{1}}^{1}\end{array}$ & $\begin{array}{l}\text { Comienzo de } \\
\text { operación en } \\
\text { Uruguay (año) }\end{array}$ & $\begin{array}{l}\text { Participación en el } \\
\text { sector (\% exporta- } \\
\text { ción para 2015) }\end{array}$ & Po $(h a)^{1}$ & $\ln$ & Me & $\mathrm{Fi}$ & $\mathrm{Te}$ & Id \\
\hline \multirow{5}{*}{$\begin{array}{l}\frac{O}{\Phi} \\
\frac{\mathcal{L}}{0} \\
\stackrel{\Xi}{J}\end{array}$} & Grupo Lactalis & Francia & 2014 & 8.8 & $x$ & $\sqrt{ }$ & $\sqrt{ }$ & $x$ & $\sqrt{ }$ & $\mathrm{x}$ \\
\hline & $\begin{array}{l}\text { Grupo Bulgheroni } \\
\text { (Estancias del Lago) }\end{array}$ & Argentina & 2015 & 3.3 & $\begin{array}{c}\sqrt{ } \\
(37000)\end{array}$ & $\sqrt{ }$ & $\sqrt{ }$ & $\sqrt{ }$ & $\sqrt{ }$ & $x$ \\
\hline & $\begin{array}{l}\text { Nestlé-DairyPartners } \\
\text { Americas }\end{array}$ & $\begin{array}{l}\text { Suizo- } \\
\text { Británico }\end{array}$ & 2010 & 1.8 & $\sqrt{ }$ & $\sqrt{ }$ & $\sqrt{ }$ & $\sqrt{ }$ & $x$ & $x$ \\
\hline & $\begin{array}{l}\text { Resto de empresas } \\
\text { uruguayas }\end{array}$ & Uruguay & & 86.1 & & & & & & \\
\hline & $\begin{array}{l}\text { Olam International } \\
\text { Limited }\end{array}$ & $\begin{array}{l}\text { India y } \\
\text { Singapur }\end{array}$ & 2007 & $x$ & $\begin{array}{c}\sqrt{ } \\
(32029)\end{array}$ & $x$ & $x$ & $\sqrt{ }$ & $\sqrt{ }$ & $x$ \\
\hline
\end{tabular}

Notas: Fases del agronegocio: Po: Productiva, In: Industrial, Me: Mercantil, Fi: Financiera, Te: Tecnológica, Id: Ideológica ${ }^{\star *}$ Refiere al año de compra del grupo corporativo en el mundo y por ende el comienzo en Uruguay.

Fuente: Elaboración propia con base en ${ }^{1}$ páginas web de las empresas; ${ }^{2}$ Uruguay XXI (2016).

En relación al sector arrocero (tabla 3), históricamente influenciado y manejado por productores brasileños en la fase productiva, durante los últimos años esto mismos han invertido en la industrial de modo creciente. En 2007, el grupo Camil, de capital brasileño, compró la principal industria del procesamiento de arroz (SAMAN) de capital nacional. En la actualidad, controla casi la mitad de las exportaciones del sector. Su estructura es oligopólica, ya que tres grupos controlan el 75\% de la industrialización y comercialización. No destacan por promoverse como impulsoras en el empleo de tecnología de punta, pero sí invierten en programas de RSE, ya que su desarrollo de actividades se localiza en regiones singulares donde tienen que existir condiciones biofísicas 
específicas para el plantío, en consecuencia, deben incidir en el territorio para evitar conflictos, dado que por sus características, su movilidad es limitada.

Tabla 3. Capital transnacional en el sector arrocero y su vinculación con las fases del agronegocio (Uruguay)

\begin{tabular}{|c|c|c|c|c|c|c|c|c|c|c|}
\hline $\begin{array}{l}\text { Sector } \\
\text { agrario }\end{array}$ & \multicolumn{4}{|c|}{ Capital } & \multicolumn{6}{|c|}{$\begin{array}{l}\text { Fases del agronegocio } \\
\text { (presencia o ausencia) }\end{array}$} \\
\hline \multirow{6}{*}{ 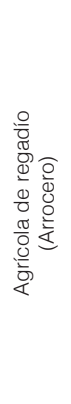 } & Nombre $^{1}$ & $\begin{array}{l}\text { Origen } \\
\text { (país) }\end{array}$ & $\begin{array}{l}\text { Comienzo de } \\
\text { operación en } \\
\text { Uruguay (año)** }\end{array}$ & $\begin{array}{l}\text { Participación en el } \\
\text { sector (\% exporta- } \\
\text { ción para 2015) }\end{array}$ & Po $(h a)^{1}$ & $\ln$ & Me & $\mathrm{Fi}$ & $\mathrm{Te}$ & Id \\
\hline & Grupo Camil & Brasil & 2007 & 46.7 & $x$ & $\sqrt{ }$ & $\sqrt{ }$ & $x$ & $x$ & $\sqrt{ }$ \\
\hline & $\begin{array}{l}\text { Grupo } \\
\text { Glencore }\end{array}$ & Suiza & 2005 & 16.7 & $\sqrt{ }$ & $\sqrt{ }$ & $\sqrt{ }$ & $\sqrt{ }$ & $x$ & $\sqrt{ }$ \\
\hline & $\begin{array}{l}\text { Union Agricul- } \\
\text { ture Group } \\
\text { (Casarone) }\end{array}$ & $\begin{array}{l}\text { Islas Vírgenes } \\
\text { (Fondos de } \\
\text { inversión }\end{array}$ & 2008 & 11.8 & $\begin{array}{c}\sqrt{ } \\
(7200)\end{array}$ & $\sqrt{ }$ & $\sqrt{ }$ & $\sqrt{ }$ & $x$ & $x$ \\
\hline & Arrozal 33 & Brasil & 1934 & 1.2 & $\sqrt{ }$ & $\sqrt{ }$ & $\sqrt{ }$ & $\sqrt{ }$ & $\sqrt{ }$ & $\sqrt{ }$ \\
\hline & $\begin{array}{l}\text { Resto de } \\
\text { empresas } \\
\text { uruguayas }\end{array}$ & Uruguay & & 23.6 & & & & & & \\
\hline
\end{tabular}

Notas: Fases del agronegocio: Po: Productiva, In: Industrial, Me: Mercantil, Fi: Financiera, Te: Tecnológica, Id: Ideológica ${ }^{*}$ Refiere al año de compra del grupo corporativo en el mundo y por ende el comienzo en Uruguay.

Fuente: Elaboración propia con base en ${ }^{1}$ páginas web de las empresas; ${ }^{2}$ Uruguay XXI (2016).

En cuanto al sector agrícola de secano (soja, trigo y maíz), en la tabla 4 se aprecia que una gran parte de las grandes transnacionales en materia agrícola opera en Uruguay (Oyhantçabal \& Narbondo, 2011), sobre todo en las fases productiva y mercantil y no tanto en la industrial; por esto hay poco valor agregado pues el grano se exporta en bruto. Además se muestra que el desembarco masivo de capitales ocurre a partir de 2002 y se intensifica al finalizar la primera década del siglo xxi, lo que ha impactado en el crecimiento de la superficie y repercutido en el volumen de las exportaciones, a tal grado que los granos han dejado atrás a la ganadería que tradicionalmente las lideraba. La falta de datos precisos sobre la cantidad de hectáreas que posee el capital transnacional impide saber la dimensión real de su extensión en el sector, pero se estima que gran parte de la superficie uruguaya destinada a la agricultura de secano, 1.4 millones de ha en 2015 (DIEA, 2016), está en sus manos. Es un sector en el que la innovación tecnológica es constante, lo que se debe a que en él dominan las empresas líderes en producción y comercialización de granos, que buscan acrecentar su productividad y plusvalía de forma permanente. En la fase financiera, destaca un conglomerado de fondos de inversión compuesto por distintas empresas en pro de la rentabilidad para los accionistas; esto ha generado la movilidad en la compra, venta y arrendamientos de tierras a lo largo y ancho del país. Mientras que en la fase ideológica se observan pocas fundaciones y vínculos con el 
territorio, ya que la alta movilidad de capitales sumada a la diversidad biofísica uruguaya para la agricultura de secano permite el desinterés por incidir territorialmente para legitimarse.

Tabla 4. Capital transnacional en el sector agrícola de secano y su vinculación con las fases del agronegocio (Uruguay)

\begin{tabular}{|c|c|c|c|c|c|c|c|c|c|c|}
\hline \multirow[t]{2}{*}{$\begin{array}{l}\text { Sector } \\
\text { agrario }\end{array}$} & \multicolumn{4}{|c|}{ Capital } & \multicolumn{6}{|c|}{$\begin{array}{l}\text { Fases del agronegocio } \\
\text { (presencia o ausencia) }\end{array}$} \\
\hline & Nombre ${ }^{1}$ & $\begin{array}{l}\text { Origen } \\
\text { (país) }\end{array}$ & $\begin{array}{l}\text { Comienzo de } \\
\text { operación en } \\
\text { Uruguay (año)** }\end{array}$ & $\begin{array}{c}\text { Participación en el } \\
\text { sector }(\% \text { exporta- } \\
\text { ción para 2015) }\end{array}$ & Po $(h a)^{1}$ & In & Me & $\mathrm{Fi}$ & $T e$ & Id \\
\hline \multirow{15}{*}{ 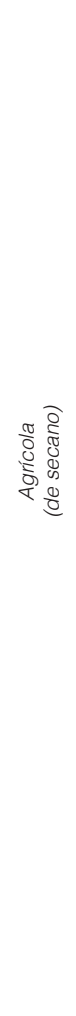 } & Cargill & $\begin{array}{l}\text { Estados } \\
\text { Unidos }\end{array}$ & 2005 & 19.0 & $\sqrt{ }$ & $x$ & $\sqrt{ }$ & $\sqrt{ }$ & $\sqrt{ }$ & $\sqrt{ }$ \\
\hline & $\begin{array}{l}\text { Grupo } \\
\text { Louis-Dreyfus }\end{array}$ & Francia & 2002 & 16.1 & $\sqrt{ }$ & $x$ & $\sqrt{ }$ & $\sqrt{ }$ & $\sqrt{ }$ & $\sqrt{ }$ \\
\hline & $\begin{array}{l}\text { William Johnson } \\
\text { y Seaboard } \\
\text { Corporation }\end{array}$ & $\begin{array}{l}\text { Uruguay- } \\
\text { Estados } \\
\text { Unidos }\end{array}$ & 2010 & 7.9 & $\sqrt{ }$ & $x$ & $\sqrt{ }$ & $\sqrt{ }$ & $x$ & $x$ \\
\hline & $\begin{array}{l}\text { AarhusKarls- } \\
\text { hamn Group }\end{array}$ & $\begin{array}{l}\text { Suecia- } \\
\text { Dinamarca }\end{array}$ & 2006 & 7.5 & $x$ & $\sqrt{ }$ & $\sqrt{ }$ & $\sqrt{ }$ & $\sqrt{ }$ & $\sqrt{ }$ \\
\hline & $\begin{array}{l}\text { Perez Companc } \\
\text { Family Group }\end{array}$ & Argentina & 2004 & 7.1 & $\sqrt{ }$ & $x$ & $\sqrt{ }$ & $\sqrt{ }$ & $x$ & $x$ \\
\hline & Kilafen & Argentina & 2003 & 6.1 & $\sqrt{ }$ & $x$ & $\sqrt{ }$ & $\sqrt{ }$ & $\sqrt{ }$ & $x$ \\
\hline & $\begin{array}{l}\text { COFCO } \\
\text { International } \\
\text { Company }\end{array}$ & China & 2016 & 4.5 & $x$ & $x$ & $\sqrt{ }$ & $\sqrt{ }$ & $\sqrt{ }$ & $x$ \\
\hline & Grupo Noble & China & 2007 & 2.3 & $\sqrt{ }$ & $x$ & $\sqrt{ }$ & $\sqrt{ }$ & $\sqrt{ }$ & $x$ \\
\hline & $\begin{array}{l}\text { Archer Daniels } \\
\text { Midland } \\
\text { Company }\end{array}$ & $\begin{array}{l}\text { Estados } \\
\text { Unidos }\end{array}$ & 2008 & 2.0 & $\sqrt{ }$ & $x$ & $\sqrt{ }$ & $\sqrt{ }$ & $\sqrt{ }$ & $x$ \\
\hline & CHS Hedging & $\begin{array}{l}\text { Estados } \\
\text { Unidos }\end{array}$ & 2015 & 2.0 & $\sqrt{ }$ & $x$ & $\sqrt{ }$ & $\sqrt{ }$ & $\sqrt{ }$ & $x$ \\
\hline & $\begin{array}{l}\text { Pacific Century } \\
\text { Group }\end{array}$ & China & 2011 & 1.9 & $\sqrt{ }$ & $x$ & $\sqrt{ }$ & $\sqrt{ }$ & $\sqrt{ }$ & $x$ \\
\hline & $\begin{array}{l}\text { Adecoagro } \\
\text { International }\end{array}$ & Luxemburgo & 2004 & 0.2 & $\begin{array}{c}\sqrt{ } \\
(3300)\end{array}$ & $x$ & $\sqrt{ }$ & $\sqrt{ }$ & $\sqrt{ }$ & $x$ \\
\hline & $\begin{array}{l}\text { Resto de empre- } \\
\text { sas uruguayas }\end{array}$ & Uruguay & & 23.4 & & & & & & \\
\hline & $\begin{array}{l}\text { Pergam-Bella- } \\
\text { mar Estancias }\end{array}$ & $\begin{array}{l}\text { Francia } \\
\text { (Fondos de } \\
\text { inversión) }\end{array}$ & 2005 & & $\begin{array}{c}\sqrt{ } \\
(10065)\end{array}$ & $x$ & $x$ & $\sqrt{ }$ & $\sqrt{ }$ & $\sqrt{ }$ \\
\hline & Okara-Trust & $\begin{array}{l}\text { Japón } \\
\text { (Fondos de } \\
\text { inversión) }\end{array}$ & 2016 & & $\begin{array}{c}\sqrt{ } \\
(10500)\end{array}$ & $x$ & $x$ & $\sqrt{ }$ & $\sqrt{ }$ & $\sqrt{ }$ \\
\hline
\end{tabular}

Notas: Fases del agronegocio: Po: Productiva, In: Industrial, Me: Mercantil, Fi: Financiera, Te: Tecnológica, Id: Ideológica. ${ }^{\star}$ Refiere al año de compra del grupo corporativo en el mundo y por ende el comienzo en Uruguay.

Fuente: Elaboración propia con base en ${ }^{1}$ páginas web de las empresas; ${ }^{2}$ Uruguay XXI (2016).

En referencia al sector forestal (tabla 5), queda de manifiesto el oligopolio de dos empresas líderes en el mundo que lo controlan prácticamente en un $75 \%$ de sus fases productiva, industrial y mercantil. Este sector expresa con más claridad el funcionamiento del agronegocio, pues tiende a dominar todas las fases, en las 
que registra un constante crecimiento y ha generado un gran impacto en la economía uruguaya debido a la integración industrial en todo el proceso productivo. Es un sector que alberga a dos plantas de producción de pulpa de celulosa y que ha recibido las mayores IED en la historia reciente del país (Uruguay XXI, 2014). Y pronto se instalará una nueva planta por parte de UPM-Kymmene Corporation, lo que posicionará a este sector como unos de los mayores exportadores agrarios en competencia directa con la agricultura y la ganadería (Presidencia de la República, 2017). Con la información que brindan la empresas se puede apreciar su acaparamiento de tierras que rebasa las 570000 ha, que además de pertenecer a empresas extranjeras representan un $60 \%$ del total de las destinadas a la forestación. Mientras que para alcanzar su viabilidad y rentabilidad, este sector ha echado mano de los fondos de inversión, en los que existe una fuerte presencia de capitales chilenos y finlandeses, esto es, los líderes mundiales en la producción forestal. En relación a la fase ideológica, es un sector que invierte mucho en los mecanismos de incidencia territorial, lo que podría estar asociado al funcionamiento propio del sector, ya que para entrar en producción requiere un plazo mínimo de ochos años antes de la primera cosecha, es por ello que se buscando evitar conflictos que dañen la inversión.

Tabla 5. Capital transnacional en el sector forestal y su vinculación con las fases del agronegocio (Uruguay)

\begin{tabular}{|c|c|c|c|c|c|c|c|c|c|c|}
\hline \multicolumn{3}{|l|}{$\begin{array}{l}\text { Sector } \\
\text { agrario }\end{array}$} & \multicolumn{2}{|l|}{ Capital } & \multicolumn{6}{|c|}{$\begin{array}{l}\text { Fases del agronegocio } \\
\text { (presencia o ausencia) }\end{array}$} \\
\hline \multirow{9}{*}{$\begin{array}{l}\bar{\pi} \\
\frac{\pi}{00} \\
\frac{0}{0} \\
\end{array}$} & Nombre $^{1}$ & $\begin{array}{l}\text { Origen } \\
\text { (país) }\end{array}$ & $\begin{array}{l}\text { Comienzo de } \\
\text { operación en } \\
\text { Uruguay (año)** }\end{array}$ & $\begin{array}{l}\text { Participación en el } \\
\text { sector (\% exporta- } \\
\text { ción para 2015) }\end{array}$ & Po $(h a)^{1}$ & In & Me & $\mathrm{Fi}$ & $\mathrm{Te}$ & Id \\
\hline & $\begin{array}{l}\text { Arauco y } \\
\text { Stora Enso }\end{array}$ & $\begin{array}{l}\text { Chile- } \\
\text { Finlandia- } \\
\text { Suecia }\end{array}$ & 2009 & 43 & $\begin{array}{c}\sqrt{ } \\
(145000)\end{array}$ & $\sqrt{ }$ & $\sqrt{ }$ & $\sqrt{ }$ & $\sqrt{ }$ & $\sqrt{ }$ \\
\hline & $\begin{array}{l}\text { UPM- } \\
\text { Kymmene }\end{array}$ & Finlandia & 2009 & 31.5 & $\begin{array}{c}\sqrt{ } \\
(215000)\end{array}$ & $\sqrt{ }$ & $\sqrt{ }$ & $\sqrt{ }$ & $\sqrt{ }$ & $\sqrt{ }$ \\
\hline & Weyerhaeuser & $\begin{array}{l}\text { Estados } \\
\text { Unidos }\end{array}$ & 1997 & 9.5 & $\begin{array}{c}\sqrt{ } \\
(132000)\end{array}$ & $\sqrt{ }$ & $\sqrt{ }$ & $\sqrt{ }$ & $\sqrt{ }$ & $\sqrt{ }$ \\
\hline & $\begin{array}{l}\text { Peter Lyford- } \\
\text { Pike }\end{array}$ & $\begin{array}{l}\text { Chile y } \\
\text { Uruguay }\end{array}$ & 2006 & 6.5 & $\begin{array}{c}\sqrt{ } \\
(45000)\end{array}$ & $x$ & $\sqrt{ }$ & $\sqrt{ }$ & $\sqrt{ }$ & $\sqrt{ }$ \\
\hline & Frutifor & Chile & 2015 & 2.9 & $\begin{array}{c}\sqrt{ } \\
(2000)\end{array}$ & $\sqrt{ }$ & $\sqrt{ }$ & $\sqrt{ }$ & $\sqrt{ }$ & $\sqrt{ }$ \\
\hline & Grupo Matte & Chile & 1994 & 2.9 & $x$ & $\sqrt{ }$ & $\sqrt{ }$ & $\sqrt{ }$ & $x$ & $\sqrt{ }$ \\
\hline & $\begin{array}{l}\text { Phaunos } \\
\text { Timber Fund }\end{array}$ & $\begin{array}{l}\text { Islas } \\
\text { Vírgenes } \\
\text { (Fondos de } \\
\text { inversión) }\end{array}$ & 2009 & 1 & $\begin{array}{c}\sqrt{ } \\
(31500)\end{array}$ & $x$ & $\sqrt{ }$ & $\sqrt{ }$ & $\sqrt{ }$ & $\sqrt{ }$ \\
\hline & $\begin{array}{l}\text { Resto de } \\
\text { empresas } \\
\text { uruguayas }\end{array}$ & Uruguay & & 2.7 & & & & & & \\
\hline
\end{tabular}

Notas: Fases del agronegocio: Po: Productiva, In: Industrial, Me: Mercantil, Fi: Financiera, Te: Tecnológica, Id: Ideológica. ${ }^{* \star}$ Refiere al año de compra del grupo corporativo en el mundo y por ende el comienzo en Uruguay.

Fuente: Elaboración propia con base en ${ }^{1}$ páginas web de las empresas; ${ }^{2}$ Uruguay XXI (2016). 
Por último, en la tabla 6 se observa que el frutícola es el de menor peso productivo en comparación con los demás sectores, tanto en superficie como en divisas exportadas. Se compone de los rubros cítrico y olivícola. En el primero destaca el Grupo San Miguel que emplea las diversas fases del agronegocio y tiene fuerte presencia de capital nacional, aunque su apertura al mercado estadounidense de 2013 lo predispone a la captación de la inversión extranjera. En el segundo destaca el monopolio del grupo Bulgheroni Nuevo Manantial que concentra más del $90 \%$ del sector y desarrolla todas las fases del agronegocio.

Tabla 6. Capital transnacional en el sector frutícola y su vinculación con las fases del agronegocio (Uruguay)

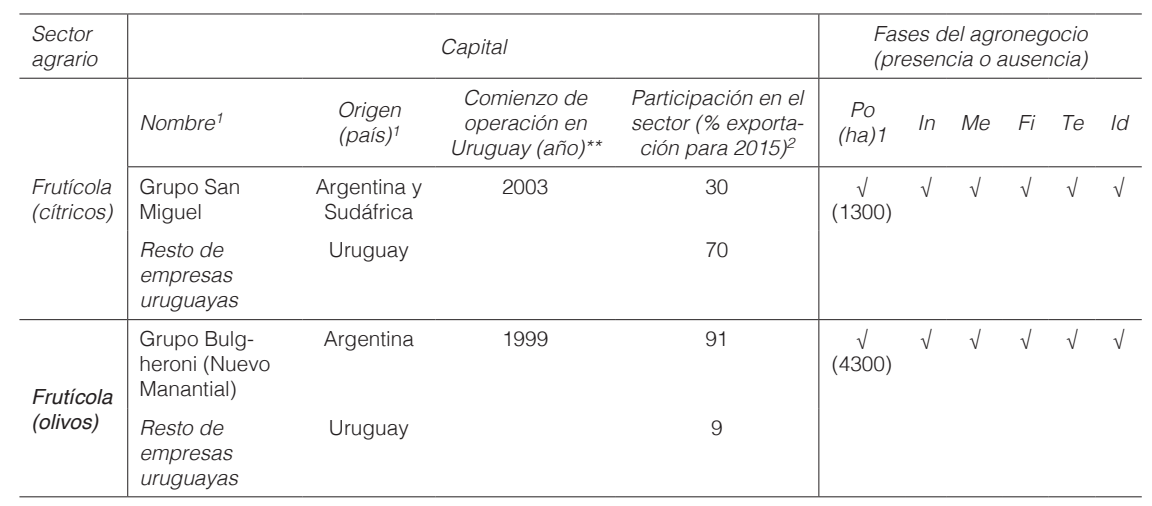

Notas: Fases del agronegocio: Po: Productiva, In: Industrial, Me: Mercantil, Fi: Financiera, Te: Tecnológica, Id: Ideológica. ${ }^{*}$ Refiere al año de compra del grupo corporativo en el mundo y por ende el comienzo en Uruguay.

Fuente: Elaboración propia con base en ${ }^{1}$ páginas web de las empresas; ' 2 Uruguay XXI (2016).

Las tablas 1-6 nos ofrecen un amplio panorama del funcionamiento del agronegocio en Uruguay. Es un modelo que se comenzó a expandir hacia 2005, en pleno auge del precio de las materias primas y la masiva llegada de IED, sobre todo a los sectores cárnico, forestal y agrícola de secano. La política económica que implementó el Estado a partir del gobierno del Frente Amplio, junto con la atractiva rentabilidad del sector a nivel mundial, ha dejado como secuela que la base del funcionamiento del sector agrario en general contenga un fuerte componente transnacional, lo evidencia la vulnerabilidad y fragilidad de la economía uruguaya. Si se suman las divisas exportadas por las empresas extranjeras del análisis de 2005, se observa que son el $24.5 \%$ del total, y que para 2015, llegaron a $41 \%$, lo que muestra el impacto directo de las empresas transnacionales en la economía del país. Pero si se analiza 
el acaparamiento de tierras queda claro que existen 783638 ha en manos de empresas extranjeras, lo que seguramente es mayor pues falta información de estos capitales. Este rasgo propio del agronegocio se expresa en el número de transacciones de compra y venta de tierras que ha sumado 5138439 de ha en el periodo 2005-2015, esto es, casi un tercio de la superficie total de Uruguay (DIEA, 2016).

Si se compara la anterior información de la posesión de tierras por empresas extranjeras en Uruguay, el dato de esta investigación no coincide, en primer lugar porque el mercado de este tipo de transacciones es muy dinámico, y en segundo porque las metodologías de recopilación son muy dispares por la escasa información que existe. Lo importante es que ambos estudios intentan aproximarse de forma precisa a un fenómeno global y creciente en los últimos ańos, en los cuales Uruguay ha sido sumamente afectado. La acumulación de datos y estudios referentes a esta temática ayuda a visualizarla y a tener elementos para el debate, pues para el Estado es un fenómeno "natural" y no es necesario un control que evite la concentración del capital y de la tierra.

En definitiva, se concluye que los sectores agropecuarios de mayor escala productiva (ganadería, agricultura, silvicultura) han aumentado considerablemente su producción en este periodo, lo que ha traído como consecuencia la disminución de las unidades productivas y un decrecimiento de la población y de los trabajadores rurales (MGAP, 2014); esto ha hecho que la estructura del espacio agrario uruguayo tenga ahora menos unidades productivas caracterizadas por la tecnificación, una mayor superficie y menos población. Se consolidan así los sectores de mayor escala en contraposición a la disminución y el desaparecimiento de las unidades productivas más pequeñas.

\section{Conclusiones}

Este artículo ha querido mostrar los elementos centrales que rigen al agronegocio en América Latina, con el ejemplo empírico de Uruguay, país que conjuga los mecanismos inherentes al funcionamiento de ese modelo. Es importante resaltar algunos aspectos.

Primero hay que mencionar el papel de Estados Unidos en la expansión ideológica y práctica del agronegocio en Latinoamérica. Un rasgo esencial del capital transnacional es que se pretende mostrar de forma natural y sin contradicciones para ocultar sus fallas. Por eso es trascendente buscar el origen y devenir histórico de los hechos, para comprender sus derivaciones y así obtener elementos más firmes para discutir por qué se imponen y ejecutan los modelos. 
En segundo lugar, cualquier imposición encuentra resistencias o aceptaciones y de allí derivan sus formas de concreción. Existen elementos comunes en la conformación del espacio latinoamericano, pero son los Estados los que, al concretar las políticas, contribuyen a la lógica global de acumulación del capital. El agronegocio pudo desarrollarse durante la crisis del periodo keynesiano y el auge del neoliberalismo porque necesitaba de Estados débiles para el desembarco masivo de las corporaciones transnacionales. Según la corriente rentista latinoamericana dentro del marxismo, ${ }^{11}$ este fenómeno - que aumenta de forma sostenida a través de la IED- ocurre porque tales corporaciones necesitan captar la renta de los países cuya economía se basa en bienes monopolizables; ${ }^{12}$ y como la renta es una ganancia extraordinaria, el capital transnacional debe sustraerla para remitirla a los países centrales. En este sentido, el agronegocio es funcional a los centros de acumulación de la riqueza.

Un tercer aspecto es el método de exposición empleado para la comprensión empírica del agronegocio. Aproximarse al funcionamiento de este modelo de forma amplia, estableciendo sus vínculos con la economía, en especial con las divisas exportadas, y discriminando por sector agrario, arroja luz sobre la composición de la estructura agraria en las etapas de su cadena productiva. Del análisis aquí presentado se rescata el aumento sostenido del capital transnacional en la totalidad de los sectores en estudio, lo que revela la trascendencia de la IED en el sector agrario, particularmente en Uruguay. Se muestra así que la base de la economía de este país está sujeta a la inversión extranjera, lo que demuestra su vulnerabilidad y fragilidad de estructura frente a las oscilaciones en el flujo de capitales. Y aunque esta política es conocida y explícita por parte de la clase política, lo que en esta investigación se intenta rescatar, es darle contenido y mostrar qué tan comprometida se encuentra la base económica actual de dicho país. Sería importante discutir las exoneraciones tributarias que, ejecutadas mediante la Comisión de la Aplicación de la Ley de Inversiones (COMAP), se otorga a los capitales extranjeros por sector. Esto daría mayor contenido a la discusión del modelo económico vigente en Uruguay.

11 Destacan los estudios de Iñigo (2007) y Kornblihtt \& Dachevsky (2010).

12 La teoría de la renta marxista afirma que tres elementos constituyen la base natural de la renta: $a$ ) el suelo es un bien natural y no producto del trabajo; $b$ ) la composición natural del suelo es diferencial, es decir, que este tiene distintas fertilidades y su cercanía al mercado consumidor también es distinta; c) el suelo es un bien limitado en su disponibilidad. En suma, el suelo es un bien natural escaso para las necesidades sociales, finito y monopolizable, lo que equivale a que se lo apropien algunos para convertirlo en un privilegio excluyente (Bartra, 2006). 
El carácter global del agronegocio, por otra parte, contribuye a entender su incidencia sobre el territorio en términos de producción de relaciones directas con los sujetos sociales. Sobre este punto cabe subrayar que el despliegue del capital en un territorio se acompaña de intereses que complementan el objetivo de acumulación de capital. Se observó que muchos capitales destinan recursos monetarios a través de la RSE para "ayudar a las comunidades" — que Santos de Souza (1999) define como el tercer sector- bajo la modalidad de organizaciones fachada. ${ }^{13}$ Es una política empresarial dual: se lucra por medio de la exoneración de impuestos, y se pretende mostrar una legitimidad dando una imagen de benefactor. El capital ofrece su rostro más humano, pero en realidad intenta el control territorial, anticipándose a los conflictos que atenten contra la inversión. Todo esto conduce a la reflexión sobre el papel del Estado, ya que muchas veces el capital que firma como RSE incide en las instituciones públicas (educación, seguridad, cultura y deporte), lo cual permite la entrada al capital en espacios que serían competencia solo del Estado. Si bien las empresas que presumen de responsabilidad social no tienen como objetivo explícito la sustitución de las funciones exclusivas del Estado, este las deja operar en su ámbito abriendo una puerta para que prime lo privado frente a lo público.

En definitiva, el agronegocio en América Latina es reflejo fiel de cómo las corporaciones van controlando los territorios e imponiendo sus condiciones para legitimar su instalación, sustituyendo con frecuencia la función del Estado y profundizando la exclusión de las pequeñas unidades productivas, que se ven imposibilitadas de enfrentar el feroz avance del capital. Así, se consolida un modelo productivo de gran escala, de producción de grandes volúmenes de materias primas, que tecnifica y transforma los paisajes en un hecho artificial; los enclaves agroproductivos consolidan el capital y así concentran un poder que se ejerce sobre distintos actores.

No es propósito de este artículo dar las pautas para saber cómo revertir tal situación, sino analizar teórica y empíricamente la realidad latinoamericana, en particular la de Uruguay, desde una mirada crítica que contribuya a reflexionar e inspirar sobre el cambio de paradigma que urge y se hace necesario cada día.

13 El tercer sector son las organizaciones que no son estatales ni mercantiles. Entre ellas se encuentran las de fachada, es decir, las que legalmente son parte de dicho sector, pero que su afán está más en lo lucrativo, pero aspiran a la aceptación social mediante mecanismos asistenciales (Santos de Souza, 1999). 


\section{Referencias}

Arbeletche, P. \& Gutiérrez, G. (2010). Crecimiento de la agricultura en Uruguay: exclusión social o integración económica en redes. Pampa. Revista Interuniversitaria de Estudios Territoriales, (6), 113-138.

Arnon, I. (1987). La modernización de la agricultura en paises en vía de desarrollo. México: Limusa.

Austin, J. (1974). Agribusiness in Latin America. Nueva York: Praeger Publishers.

Bartra, A. (2006). El capital en su laberinto: De la renta de la tierra a la renta de la vida. México: $\mathrm{UACM} /$ Ítaca.

Borras Jr., S. M., Franco, J. C., Gómez, S., Kay, C. \& Spoor, M. (2012). Land grabbing in Latin America and the Caribbean. The Journal of Peasant Studies, 39(3-4), 845-872.

Brunhoff, S. de. (1978). La politica monetaria: un ensayo de interpretación marxista (2a ed.). México: Siglo XXI.

Burbach, R. \& Flynn, P. (1980). Agribusiness in the Americas. Nueva York: Monthly Review Press.

Calderón, G. (2006). La inserción del capital en los espacios rurales e indígenas en México. En Geraiges de Lemos, A. I., Arroyo, M. \& Silveira, M. L. (Eds.). América Latina: cidade, campo e turismo (pp. 243-261). San Pablo: CLACSO.

Carrasco, A. E., Sánchez, N. E. \& Tamango, L. E. (2012). Modelo agrícola e impacto socio-ambiental en la Argentina: monocultivo y agronegocios. La Plata: AUGM.

Castillo, E. (2012). El auge de la agricultura especulativa y la expansión de la crisis alimentaria global, en el marco del régimen corporativo de alimentos 2006-2009. México: UNAM.

Cattani, D. (2009). Fraudes corporativos y apropiación de la riqueza. Convergencia, 16(51), 59-84.

Cepal. (2016). La Inversión Extranjera Directa en América Latina y el Caribe (2016). Santiago de Chile: CEPAL.

Cepal. (2015). Anuario Estadístico de América Latina y el Caribe 2014. Santiago de Chile: CEPAL.

Cubbage, F., Koesbandana, S., Mac Donagh, P., Rubilar, R., Balmelli, G., Olmos, V., et al. (2010). Global timber investments, wood costs, regulation, and risk. Biomass and Bioenergy, 34(12), 1667-1678. 
Cueva, A. (1979). El desarrollo del capitalismo en América Latina (3a. ed.). México: Siglo XXI.

Chesnais, F. (2005). A finança mundializada. São Paulo: Boitempo.

Davis, J. \& Goldberg, R. (1957). A concept of agribusiness. Boston: Harvard University Graduate School of Business Administration.

DIEA. (2016). Anuario 2015. Montevideo: Dirección Estadísticas Agropecuarias.

Dirven, M. (1999). El papel de los agentes en las políticas agrícolas: Intenciones y realidad. Revista de la CEPAL, 68(1), 171-186.

FAO. (2015). FAOESTAT. Recuperado el 10 de agosto de 2015, de http://faostat3.fao.org/

FAO. (2011). El acaparamiento de tierras en América Latina y el Caribe visto desde una perspectiva internacional más amplia. Roma: FAO.

FARM. (2017). Federaciones de Asociaciones Rurales del Mercosur. Recuperado el 18 de mayo de 2015, de http://www.farmercosur.org

Fecagro. (2017). Federación Centroamericana de Cámaras Agropecuarias y Agroindustriales. Recuperado el 18 de mayo de 2015, de http://www.fecagro.org

Felici, I. (1996). La colonia Cecilia. Fra leggenda e realtà. Rivista storica dell'anarchismo, (2), 103-109.

Felicio, M. J. (2011). Contribuição ao debate paradigmático da questão agrária e do capitalismo agrário. Tesis de doctorado en Geografía. Universidade Estadual Paulista. Presidente Prudente.

Fernandes, B. (2013). Construindo um estilo de pensamento na questão agrária: o debate paradigmático e o conhecimento geográfico. Presidente Prudente: Universidade Estadual Paulista.

Fernandes, B. \& Welch, C. (2008). Campesinato e agronegócio da laranja nos EUA e Brasil. En Fernández, B. (Ed.). Campesinato e agronegócio na América Latina: a questão agrária atual (pp. 45-70). São Paulo: Expressão Popular.

Florit, P. \& Piedracueva, M. (2017). Agronegocio y corporaciones transnacionales: Modelando el Uruguay dependiente. Nómadas. Revista Crítica de Ciencias Sociales y Jurídicas, 1(50), 299-326.

Galeano, E. (2004). Las venas abiertas de América Latina. México: Siglo XXI. 
Goldberg, R. (1974). Agribusiness Management for Developing Countries-Latin America. Cambridge: Ballinger.

Gras, C. \& Hernández, V. (2013). El agro como negocio. Producción, sociedad y territorios en la globalización. Buenos Aires: Biblos.

Griffin, K. (1982). La economia política del cambio agrario. México: FCE.

Grosso, S., Bellini, M. E., Qüesta, L., Guibert, M., Lauxmann, S. \& Rotondi, F. (2010). Impactos de los "pools de siembra" en la estructura social agraria: Una aproximación a las transformaciones en los espacios centrales de la provincia de Santa Fe (Argentina). Revista de Estudios Regionales y Mercado de Trabajo, 1(6), 115-138.

Harvey, D. (2005). A Brief History of Neoliberalism. Nueva York: Oxford University.

Hernández, V. (2007). El fenómeno económico y cultural del boom de la soja y el empresariado innovador. Desarrollo Económico, 47(187), 331-335.

IICA. (2010). Desarrollo de los agronegocios y la agroindustria en América Latina y el Caribe. Conceptos, instrumentos y casos de cooperación técnica. San José de Costa Rica: IICA.

INAC. (2017). Anuario estadístico 2016. Montevideo: Instituto Nacional de Carnes.

Iñigo Carrera, J. (2007). La formación económica de la sociedad Argentina 1882-2004. Buenos Aires: Imago Mundi.

Kornblihtt, J. \& Dachevsky, F. (2010). Notas metodológicas para el cálculo de la renta de la tierra petrolera. Economia: teoría y práctica, 1(33).

La Vía Campesina. (2017). La Vía Campesina: Movimiento Campesino Internacional. Recuperado el 17 de mayo de 2017, de https://viacampesina.org

LAND Matrix. (2016). The Online Public Database on Land Deals. Recuperado el 3 de mayo de 2017, de http://www.landmatrix.org/en/get-the-detail/by-target-country/uruguay/

Leff, E. (1994). Ecología y capital: racionalidad ambiental, democracia participativa y desarrollo sustentable. México: Siglo XXI.

León, E. (2011). Territorialidad campesina y contrarreforma agraria neoliberal en México. En León, E. y Calderón, G. (Eds.). Descubriendo la espacialidad social desde América Latina, vol. 1 (pp. 179-208). México: Ítaca. 
Marcos, V. de. (1998). A comunidade Sinsei e a (U) topia da produção. GEOUSP: Espaço e Tempo, (2), $41-47$.

Marichal, C. (2010). Nueva historia de las grandes crisis financieras: una perspectiva global, 18732008. Buenos Aires: Debate.

Mgap. (2014). Censo General Agropecuario 2011: Resultados Definitivos. Montevideo: Ministerio Ganadería Agricultura Pesca.

Neto, C. de Mello (1996). O anarquismo experimental de Giovanni Rossi. Ponta Grossa: UePG.

Olarte, S. (2012). Un nuevo paradigma de agronegocio sostenible: análisis y propuesta teórica. Agroalimentaria, 18(35), 31-42.

Oliveros Espinosa, R. G. (2014). Escala Análisis Espacial del Movimiento Zapatista. Artículo presentado en el XIII Coloquio Internacional de Geocrítica "El control del espacio y los espacios de control". Barcelona, 5 al 10 de mayo.

OMC. (2015). Organización Mundial del Comercio. Recuperado el 18 de agosto de 2015, de https://www.wto.org/english/thewto_e/whatis_e/tif_e/agrm8_e.htm

Oyhantçabal, G. \& Narbondo, I. (2011). Radiografía del agronegocio sojero: Descripción de los principales actores y los impactos socio-económicos en Uruguay. Montevideo: REDES-AT.

Oyhantçabal, G., Narbondo, I. \& Areosa, P. (2014). ¿Acaparamiento de tierras en Uruguay? Artículo presentado en el $2^{\circ}$ Congreso de Ciencias Sociales Agrarias. Salto, 6 al 8 de agosto.

Perkins, J. (1997). Geopolitics and the green revolution: wheat, genes and the cold war. Nueva York: Oxford University.

Piccolo, F. (2009). Progettare le identità del territorio. Piani e interventi per uno sviluppo locale autosostenibile nel paesaggio agricolo della Valle dei Templi di Agrigento. Firenze: Alinea Editrice.

Presidencia de la República Oriental del Uruguay. (2017). Gobierno avanza en negociaciones con UPM. Recuperado el 13 de mayo de 2017, de https://www.presidencia.gub.uy/sala-de -medios/videos/gobierno+avanza+en+negociaciones+con+upm

REDES-AT. (2012). Agentes Empresariales del Agronegocio. Uruguay/Informe 2012. Montevideo: REDES-AT.

Ross, R. (2000). Mission possible: The Latin American Agribusiness Development Corporation. New Brunswick: Transaction Publishers. 
Rubio, B. (2012). Explotados y excluidos: los campesinos lationoamericanos en la fase agroexportadora neoliberal. México: Plaza y Valdés.

Rulli, M. C., Saviori, A. \& D’Odorico, P. (2012). Global land and water grabbing. PNAs, 110(3), 892-897.

Santos, B. de Souza. (1999). La reinvención solidaria y participativa del Estado. En Santos, B. de Souza (Ed.). Reinventar la democracia, reinventar el Estado (pp. 49-87). Madrid: Sequitur.

unCTAD. (2009). Transnational Corporations, Agricultural Production and Development. Ginebra: United Nations Conference on Trade and Development.

Uruguay XXI. (2016a). Exportaciones por Empresas, series históricas. Recuperado el 20 de abril de 2017, de http://www.uruguayxxi.gub.uy/informacion/knowledge-base/empresas/

Uruguay XXI. (2016b). Oportunidades de inversión: AGRONEGOCIOS. Montevideo: Instituto Uruguay XXI.

Uruguay XXI. (2014). Comportamiento Exportador de las Empresas Extranjeras en Uruguay. Montevideo: Instituto Uruguay XXI.

Vergopoulos, K. (2014). La crisis financiera y alimentaria mundial. Artículo presentado en IX alasru. Ciudad de México, 6 al 10 de octubre.

\section{Anexo 1}

Tabla 7. Correspondencia entre el nombre del capital y la razón social

\begin{tabular}{l|l|l}
\hline $\begin{array}{l}\text { Sector } \\
\text { agrario }\end{array}$ & $\begin{array}{l}\text { Nombre del } \\
\text { capital }\end{array}$ & $\begin{array}{l}\text { Nombre de la empresa } \\
\text { (razón social) }\end{array}$ \\
\hline \multirow{4}{*}{ Grupo Marfrig } & $\begin{array}{l}\text { Frigorífico Tacuarembó, S. A. } \\
\text { Establecimientos Colonia, S. A. } \\
\text { Inaler, S. A. } \\
\text { Cledinor, S. A. }\end{array}$ \\
\cline { 2 - 3 } & \multirow{4}{*}{ Grupo Minerva Foods } & $\begin{array}{l}\text { Pul, S. A. } \\
\text { Frigorífico Matadero Carrasco } \\
\text { (Frimacar, S. A. ) } \\
\text { Frigorífico Canelones, S. A. }\end{array}$ \\
\cline { 2 - 3 } & Nipponham Group & Breeders \& Packers Uruguay, S. A. \\
\cline { 2 - 3 } & Heilongjiang Foresun & Frigorífico Melilla (Lorsinal, S. A.) \\
Agriculture Group & Frigorífico Rosario (Rondatel, S. A.) \\
\cline { 2 - 3 } & Eurofrance & Herbal Paradise, S. A. \\
\cline { 2 - 3 } & Hijazi y Ghosheh Group & Gladenur, S. A. \\
\cline { 2 - 3 } & Union Agriculture Group & UAG, S. A. \\
\hline
\end{tabular}


Tabla 7. Continuación

\begin{tabular}{|c|c|c|}
\hline $\begin{array}{l}\text { Sector } \\
\text { agrario }\end{array}$ & $\begin{array}{l}\text { Nombre del } \\
\text { capital }\end{array}$ & $\begin{array}{l}\text { Nombre de la empresa } \\
\text { (razón social) }\end{array}$ \\
\hline \multirow{4}{*}{ Lechero } & Grupo Lactalis & Industria Láctea Salteña S. A. \\
\hline & $\begin{array}{l}\text { Grupo Bulgheroni } \\
\text { (Estancias del Lago) }\end{array}$ & Estancias del Lago, S. R. L. \\
\hline & $\begin{array}{l}\text { Nestlé } \\
\text { Dairy Partners Americas }\end{array}$ & Dairy Partners Uruguay, S. A. \\
\hline & $\begin{array}{l}\text { Olam International } \\
\text { Limited }\end{array}$ & NZ Farming Systems Uruguay, S. A. \\
\hline \multirow{4}{*}{$\begin{array}{l}\text { Agrícola de } \\
\text { regadío (arrocero) }\end{array}$} & Grupo Camil & S. A. M. A. N. S. A. \\
\hline & Grupo Glencore & Glencore, S. A. \\
\hline & Union Agriculture Group & Casarone Agroindustrial, S. A. \\
\hline & Arrozal 33 & Arrozal 33, S. A. \\
\hline \multirow{14}{*}{ Agrícola de (secano) } & Cargill & Crop Uruguay, S. A. \\
\hline & Grupo Louis-Dreyfus & LDC Uruguay, S. A. \\
\hline & $\begin{array}{l}\text { William Johnson y } \\
\text { Seaboard Corporation }\end{array}$ & Cereoil Uruguay, S. A. \\
\hline & AarhusKarlshamn Group & Aarhuskarlshamn Latin America, S. A. \\
\hline & $\begin{array}{l}\text { Perez Companc } \\
\text { Family Group }\end{array}$ & Garmet, S. A. \\
\hline & Kilafen & Kilafen, S. A. \\
\hline & $\begin{array}{l}\text { COFCO International } \\
\text { Company }\end{array}$ & Nidera Uruguay, S. A. \\
\hline & Grupo Noble & Evera, S. A. \\
\hline & $\begin{array}{l}\text { Archer Daniels Midland } \\
\text { Company }\end{array}$ & ADM Uruguay, S. A. \\
\hline & CHS Hedging & CHS Uruguay, S. R. L. \\
\hline & Pacífico Century Group & TGL Uruguay, S. A. \\
\hline & Adecoagro International & Adecoagro, S. A. \\
\hline & $\begin{array}{l}\text { Pergam - Bellamar } \\
\text { Estancias }\end{array}$ & Campos Orientales, S. A. \\
\hline & Okara - Trust & Campos Orientales, S. A. \\
\hline \multirow{7}{*}{ Forestal } & Arauco y Stora Enso & Eeufores, S. A. \\
\hline & UPM-Kymmene & Compañía Forestal Oriental, S. A. \\
\hline & Weyerhaeuser & Los Piques, S. A. \\
\hline & Peter Lyford-Pike & Forestal Atlántico Sur, S. A. \\
\hline & Frutifor & Urupanel, S. A. \\
\hline & Grupo Matte & Industria Papelera Uruguaya, S. A. \\
\hline & Phaunos Timber Fund & $\begin{array}{l}\text { Pradera Roja, S. A. } \\
\text { Caldrey, S. A. }\end{array}$ \\
\hline Frutícola (cítricos) & Grupo San Miguel & Milagro, S. A. \\
\hline Frutícola (olivos) & $\begin{array}{l}\text { Grupo Bulgheroni } \\
\text { (Nuevo Manantial) }\end{array}$ & Agroland, S. A. \\
\hline
\end{tabular}

Fuente: Elaboración propia con base en Uruguay XXI (2016a).

M. Ceroni | Rasgos centrales del agronegocio en Latinoamérica: la experiencia en Uruguay Perfiles Latinoamericanos, 26(52) | FLACso México | DoI: 10.18504/pl2652-004-2018 